\title{
A OUVIDORIA À LUZ DA ANÁLISE DE CONTEÚDO
}

\author{
(The Ombudsman in Light of Content Analysis)
}

\author{
Leandro Lombardi ${ }^{1}$ \\ Universidade Federal de Goiás \\ Solon Bevilacqua ${ }^{2}$ \\ Universidade Federal de Goiás
}

\begin{abstract}
RESUMO
Reconhecidas como instrumento de participação social, as ouvidorias públicas possuem a competência de aproximar os cidadãos das instituições. Com o objetivo de aprimorar o processo de resolução de problemas $e$ dos pedidos de informação, foram aplicadas técnicas estatísticas nos termos linguísticos de uma base textual de solicitações remetidas à ouvidoria. Utilizando a metodologia de Análise de Conteúdo e com o auxílio do programa Iramuteq, foi proposta uma tipologia personalizada para a classificação das demandas recebidas pelas ouvidorias por meio das técnicas de Classificação Hierárquica Descendente e de Análise Fatorial por Correspondência. Conclui-se que a nova tipologia fortalece a relação cidadão-instituição por ter sido formulada a partir das necessidades do seu público-alvo, e que a metodologia utilizada pode ser replicada em outras organizações, sejam elas públicas ou privadas.
\end{abstract}

Palavras-chave: Participação Social. Ouvidoria. Análise de Conteúdo. Iramuteq.

\begin{abstract}
Recognized as an instrument of social participation, public ombudsmen have the competence to bring citizens closer to institutions. In order to improve the problem solving process and the requests for information, statistical techniques were applied in linguistic terms of a textual base of requests sent to the ombudsman. Using the Content Analysis methodology and with the help of the Iramuteq software, a customized typology was proposed in order to classify the demands received by the ombudsmen using the techniques of Hierarchical Descending Classification and Factorial Analysis by Correspondence. It is concluded that the new typology strengthens the citizen-institution relationship since it has been formulated based upon the needs of its target audience, and also that the methodology used can be replicated in other organizations, whether public or private.
\end{abstract}

Keywords: Social Participation. Ombudsman. Content analysis. Iramuteq.

Recebido em: agosto 2018

Aceito em: fevereiro 2019

DOI: $10.26512 /$ les.v20i1.11275

\footnotetext{
${ }^{1}$ Mestre em Administração Pública pela Universidade Federal de Goiás (2018), possui especialização em Ciência da Informação e graduação em Administração pela Universidade de Brasília. Atualmente exerce o cargo de Analista Executivo no Inmetro. Possui experiência na área de Gestão Pública e Ciência da Informação, atuando principalmente nos seguintes temas: participação social, transparência, inteligência competitiva, pesquisa de marketing e gestão da informação. E-mail: lelombardi@gmail.com

${ }^{2}$ Possui graduação em Administração pela Universidade Federal do Rio Grande do Sul, mestrado em Administração pela Universidade Federal de Uberlândia e doutorado em Psicologia pela Pontifícia Universidade Católica de Goiás. Atualmente é professor efetivo da Universidade Federal de Goiás e encontra-se vinculado ao Mestrado Profissional em Gestão Pública Profiap/UFG. Como pesquisador, é líder do Grupo de Pesquisa M2C Estudos de Mercado, Consumidor e Consumo. E-mail: solbev@gmail.com
} 


\section{INTRODUÇÃO}

Dentre as modernas formas de participação social elencadas pela literatura, a ouvidoria pública se destaca ao representar um caminho direto para a ciência dos anseios e problemas dos cidadãos. Além disso, também possui a função de mediar o relacionamento entre organizações, clientes e usuários nas questões que extrapolam o atendimento ordinário. Para tanto, é importante que as ouvidorias trabalhem para superar as expectativas daqueles que as procuram, pois, em muitos casos, trata-se do último recurso para a resolução de conflitos no âmbito administrativo.

Conforme observado por Rabelo e Alencar (2016), ao ouvir o cidadão, as ouvidorias possuem o potencial de aproximar o serviço público do ideal de Estado democrático, transformando o diálogo em aperfeiçoamento para a gestão pública. Segundo os autores, devido a sua importância, a revisão sistematizada do processo de atendimento das ouvidorias públicas estimula a ampliação contínua da qualidade e da satisfação perante os serviços oferecidos pelas organizações.

Mesmo diante da sua importância institucional, pesquisas sobre as ouvidorias apontam para certa subutilização desse canal no âmbito governamental, demonstrando diversas oportunidades de melhorias nas unidades de atendimento, incluindo ações mais proativas que visem à ampliação da participação social (MENEZES, 2015; SILVA et al., 2012).

Tradicionalmente, as demandas que chegam às ouvidorias seguem uma lógica semelhante de segmentação, normalmente classificando os registros em: reclamação, pedido de informação, denúncia, sugestão, crítica e elogio (BRASIL, 2014). Essa visão remete às estruturas mecanicistas dos call centers, caracterizadas pela rotina, formalização e centralização das atividades (AZEVEDO; CALDAS, 2005). Embora amplamente utilizado, este modelo tende a engessar a estrutura organizacional ao criar uma rotina voltada para o ambiente interno, além de limitar o espaço para o entendimento e aprofundamento das questões que fogem da rotina (MORGAN, 2006).

Este estudo, de caráter qualitativo e exploratório, se propôs a rever essa classificação tradicional utilizando a metodologia da Análise de Conteúdo (AC) nos registros encaminhados à Ouvidoria do Instituto Nacional de Metrologia, Qualidade e Tecnologia (Inmetro). Assim, com o auxílio do programa Iramuteq, foi proposta uma tipologia personalizada dos registros recebidos, utilizando o próprio conteúdo lexicográfico das demandas para gerar uma segmentação que pudesse tornar mais ágil a triagem das informações e resolução das solicitações.

A AC utiliza procedimentos estatísticos para a medição da frequência dos temas presente nos registros para comparar os elementos textuais (palavras e frases) de forma a compor classes (clusters) de elementos com significados próximos (NASCIMENTO; MENANDRO, 2006). 
Neste contexto, a utilização de programas informatizados de análise lexicográfica é recomendada quando o volume de informações textuais inviabiliza o estudo pelas ferramentas tradicionais (CHARTIER; MEUNIER, 2011). Devido à quantidade significativa de registros coletados, optou-se pela utilização do software Iramuteq.

A melhoria na gestão das ouvidorias, esperado a partir da análise de suas demandas, poderá influir nos seguintes aspectos organizacionais: reduzir o tempo médio de atendimento, melhorar o processo de triagem das informações, aumentar a satisfação com a resposta dada às solicitações e embasar futuras ações de treinamento e capacitação.

Para melhor compreensão do tema proposto, o artigo foi divido da seguinte forma: na primeira seção, foi ressaltada a importância da ouvidoria como instrumento democrático de participação popular. Em seguida, fez-se um breve ensaio sobre a AC - visto que a utilização dessa metodologia ainda encontra-se em fase de crescimento no meio científico brasileiro (INFANTOSI; COSTA; ALMEIDA, 2014) - e também sobre o programa Iramuteq. Na seção dedicada aos Procedimentos Metodológicos, foram descritas as técnicas utilizadas para a realização do Estudo de Caso, cujos resultados compõem um capítulo à parte, com as figuras e tabela extraídas do programa. Por fim, nas Considerações Finais, foram relatadas as principais conclusões da pesquisa e suas limitações.

\section{DA PARTICIPAÇÃO SOCIAL ÀS OUVIDORIAS PÚBLICAS}

Uma característica que se destaca nas democracias mais consolidadas é a efetiva participação da sociedade nos assuntos de interesse público. Conforme ressaltado por Bobbio (2005), o nível de desenvolvimento democrático das nações não se restringe à mensuração do número de pessoas que votam, mas na quantidade de instâncias disponíveis para receber os anseios dos cidadãos. Por conseguinte, ao terem suas demandas acolhidas pelas organizações públicas, os cidadãos estão exercendo um direito tão importante quanto o voto para a cidadania.

Esse alargamento do conceito de democracia foi substanciado por meio de iniciativas que visaram ampliar a participação da sociedade para além da esfera política, com o objetivo de aproximar a administração pública do cidadão e incentivar e ampliar o controle social (POGREBINSCHI; SANTOS, 2011). Neste contexto, a administração pública deve adotar os preceitos da transparência ao prover os caminhos para que os cidadãos possam acompanhar e fiscalizar as ações realizadas, de forma a reforçar a legitimidade das instituições (RAUPP, 2016).

A participação da sociedade nas ações dos governos também visa combater a atual crise da democracia representativa, cujas características incluem: falta de interesse dos eleitores sobre 
questões relacionadas à política, apatia da população para com assuntos públicos e elevada incidência de denúncias de corrupção na administração pública (MILANI, 2008).

A ocorrência dessas características evidencia um distanciamento entre a representação política e a vontade dos representados. Na tentativa de reverter esse quadro, algumas iniciativas governamentais buscam a redefinição deste modelo, por meio da materialização de mecanismos de participação popular e transparência da gestão do Estado. Como exemplo de tais mecanismos, têmse a implementação de audiências e consultas públicas, além da atuação de ouvidores nos órgãos da Administração (SOARES, 2002).

Nesse contexto, ressalta-se o papel das ouvidorias públicas, que além de oferecer uma escuta qualificada aos problemas dos cidadãos, também promovem maneiras eficazes de concretização de direitos, gerando oportunidades para que as instituições melhorem seus procedimentos de forma a beneficiar toda a coletividade (MENEZES, 2015).

Peixoto, Marsiglia e Morrone (2013), em pesquisa sobre o tema, fazem uma ampla contextualização histórica desde o surgimento das ouvidoras até o seu papel nos dias atuais. Resumidamente, a ouvidoria, ou ombudsman, surgiu na Suécia no século XVIII com a função de representar o Rei, que por vários anos se ausentava do país em função das guerras. Mais tarde, em 1809, a função foi modificada para que o responsável pudesse defender o povo contra o excesso de burocracia dos assuntos de competência do Estado. Ao longo dos anos, a função evoluiu, passando a representar um meio de intercessão entre a administração pública e a população. Inicialmente no Brasil, o Ouvidor, termo mais comumente utilizado, possuía a função de reportar ao Rei de Portugal os acontecimentos de sua colônia. Com a instituição da República, passou a exercer a função de "Juiz do Povo". A primeira ouvidoria pública do Brasil, a Ouvidoria Municipal de Curitiba, surgiu em 1968. Contudo, foi somente na década de 1990 que as ouvidorias ganharam destaque na gestão pública brasileira.

Atualmente, as ouvidorias funcionam como um espaço institucional da manifestação da pluralidade de interessados na esfera pública ao proverem um elo, na forma da participação social, entre o cidadão e a Administração Pública (SILVA et al., 2012).

No mesmo sentido, o Manual de Ouvidoria Pública, desenvolvido pela Ouvidoria-Geral da União (BRASIL, 2013), ressalta que as ouvidorias públicas funcionam como intermediadoras entre o Estado e seus cidadãos ao permitirem que as demandas e os anseios da sociedade sejam ouvidos pela Administração Pública. Esta, por sua vez, deve buscar utilizar essas informações como insumos para o desenvolvimento de melhorarias na gestão dos processos e aumento da satisfação das pessoas com os serviços recebidos, além disso, ressalta-se que os estados democráticos utilizam 
as ouvidorias como espaços de manifestações plurais, que servem de instâncias de controle, participação e de gestão das políticas públicas.

Para Barreto e Alves Filho (2016, p. 159), a ouvidoria "é o melhor canal para entender o que o cidadão demanda e espera do serviço público”. Segundo os autores, a essência do serviço da ouvidoria é a interlocução entre o cidadão e a prestação do serviço, que deve buscar a melhoria constante do atendimento prestado.

Entretanto, apesar da relevância desse tipo de canal como espaço de diálogo e de garantia de direitos, uma pesquisa com a população do Estado de Minas Gerais, intitulada "Por um Sistema Nacional de Ouvidorias Públicas: possibilidades e obstáculos" e patrocinada pela Secretaria de Assuntos Legislativos do Ministério da Justiça, demonstrou uma série de dificuldades estruturais e conjunturais das ouvidorias públicas pesquisadas. Como consequência, 81,7\% dos entrevistados declararam que gostariam de fazer alguma reclamação ao governo, porém, 32\% nunca ouviram falar em ouvidorias públicas. O estudo ressaltou que, por falta de conhecimento, apenas uma parcela ínfima da população se propõe a levar suas demandas a essas ouvidorias (SILVA et al., 2012).

\section{Sobre a AnÁlise de Conteúdo na PESQuisa CiEntífica}

Dentre as formas de condução das pesquisas científicas, Creswell (2007) faz referência a três modelos: o método qualitativo, o quantitativo e o tipo misto.

A abordagem qualitativa é utilizada quando existe a necessidade de observação holística de determinados fenômenos. Por se tratar de uma metodologia eminentemente interpretativa, nela são levantadas as considerações dos atores imersos em seus respectivos contextos, determinando as razões para a ocorrência dos objetos de estudo (FREGONEZE et al., 2014). Na técnica qualitativa de coleta dos dados, "o pesquisador tenta estabelecer o significado de um fenômeno a partir do ponto de vista dos participantes" (CRESWELL, 2007, p. 37). Além disso, a técnica é direcionada para a elaboração de novas hipóteses e construção de indicadores qualitativos por meio da análise de documentos e de discursos das histórias sociais sob o ponto de vista de quem as vivenciou (MINAYO, 2014).

Já na abordagem quantitativa, são utilizadas técnicas estatísticas para explicar os fenômenos objeto de estudo, transformando-os em variáveis passíveis de extrapolação por meio da medição estatística das ocorrências (FREGONEZE et al., 2014).

É importante ressaltar que a abordagem qualitativa não exclui o uso de técnicas quantitativas. De fato, Minayo (2014) ressalta a imprecisão da dicotomia entre os estudos 
qualitativos e quantitativos, tendo em vista que dentro do campo da Pesquisa Social, os fenômenos apresentam características numéricas e características valorativas - muitas vezes de forma inseparável e interdependente - e sem que haja prioridade de uma sobre a outra.

De fato, uma das preocupações das pesquisas qualitativas refere-se à sua representatividade, isto é, até quanto a fala de alguns pode retratar a fala de muitos?

Uma das soluções para essa questão está na utilização de métodos mistos para a coleta e tratamento dos dados da pesquisa, obtendo informações numéricas e textuais com o objetivo de formar um banco de dados com recursos qualitativos e quantitativos para análises sequenciais ou conjuntas (CRESWELL, 2007). Além disso, a aproximação das duas técnicas é capaz de promover a construção de um modelo mais próximo da realidade observada, além de ensejar a criação de novas teorias colaborativas (MINAYO, 2014).

Dentre as diversas técnicas estatísticas de análise dos dados qualitativos, a Análise de Conteúdo (AC) é uma das mais utilizadas no meio científico (MINAYO, 2014).

$\mathrm{A} \mathrm{AC}$ é um conjunto de técnicas metodológicas aplicadas à comunicação que vão desde o cálculo de frequência até a representação de modelos baseados em dedução e passíveis de inferência (BARDIN, 2011). Nesse sentido, "a análise de conteúdo, como técnica de tratamento de dados, possui a mesma lógica das metodologias quantitativas, uma vez que busca a interpretação cifrada do material de caráter qualitativo" (MINAYO, 2014, p. 304).

Sabe-se que a fala do indivíduo obedece a padrões e comportamentos sociais e a modelos interiorizados, que são as chaves da representatividade do grupo na linguagem do indivíduo, mesmo frente às variações das expressões pessoais (MINAYO, 2014). Desta forma, por meio da análise léxica e outras técnicas, busca-se aplicar métodos objetivos e sistemáticos para avaliar o conteúdo das mensagens, como o dimensionamento das frases e a verificação da frequência com que vocábulos ou ideias aparecem em uma amostra (BARDIN, 2011; MINAYO, 2014; NASCIMENTO; MENANDRO, 2006).

Na metodologia de AC, a inferência parte do princípio de que ao se analisar o conteúdo de um texto, as características encontradas e classificadas na mensagem correspondem, por meio de deduções lógicas e devidamente justificadas, às características culturais, psicológicas, sociológicas e históricas daqueles que a produziu. Para tanto, a técnica leva em consideração não somente o conteúdo (significados), mas também a forma e a distribuição daquilo que é expresso por meio das mensagens (BARDIN, 2011). Nas palavras de Minayo (2014, p. 308), busca-se "relacionar estruturas semânticas (significantes) com estruturas sociológicas (significados)".

Por preocupar-se com a replicação dos resultados obtidos, o tratamento de dados textuais, no contexto da AC, é um método interdisciplinar que permite a extração de informações contidas 
em um grande número de textos, envolvendo a combinação de hermenêutica com a genealogia da produção discursiva (PLUMECOCQ, 2014).

A utilização de técnicas quantitativas aplicadas à $\mathrm{AC}$ visa à diminuição da subjetividade da avaliação ao demonstrar estatisticamente as diversas relações de "atração" e "repulsão" entre as variáveis, objeto de estudo (INFANTOSI; COSTA; ALMEIDA, 2014).

Nesse contexto, os recursos computacionais possuem um papel de destaque na superação da dicotomia qualitativa / quantitativa ao permitir a automatização dos procedimentos de codificação e distribuição de frequência das unidades textuais e das análises de seus conteúdos, ampliando consideravelmente as possibilidades de estudos. Utilizando softwares automatizados, é possível a interpretação de um significativo volume de textos com o objetivo de explicar o universo por meio da inferência estatística de um determinado grupo estudado (BARDIN, 2011).

Minayo (2014) ensina que, dentro do ambiente da AC, a análise lexical é uma técnica que se dedica ao estudo estatístico do vocabulário do locutor por meio da avaliação quantitativa (frequência) com que as palavras e frases aparecem nos textos analisados. Para tanto, deve-se primeiramente identificar o número total de ocorrência das palavras e então separá-las de acordo com sua classificação morfológica. A seguir, são excluídas as palavras e classes de palavras de baixo interesse até que o resultado final represente o sentido daquilo que é comunicado. Então, são utilizadas técnicas estatísticas mais robustas, como análises bi ou multivariadas, para apoiar os resultados analíticos quantitativos.

O estudo da linguagem e de seu conteúdo simbólico por meio da análise de dados textuais refere-se essencialmente ao estudo sobre o comportamento humano, como pensamentos, opiniões e crenças. Nesse contexto, o uso de softwares vem auxiliando os pesquisadores da área das Ciências Humanas, sobretudo quando o volume de dados é significativo (CAMARGO; JUSTO, 2013).

Neste estudo, o programa escolhido para apoiar o estudo de análise lexical foi o Iramuteq.

\section{O IRAMUTEQ}

O software Iramuteq (Interface de R pour les Analyses Multidimensionnelles de Textes et de Questionnaires), desenvolvido em plataforma de código aberto e distribuído de forma gratuita, oferece diversas formas de análises de textos, que vão desde lematização e o cálculo da frequência de palavras até análises multivariadas com resultados organizados de forma clara e de fácil compreensão (CAMARGO; JUSTO, 2013).

O programa facilita a interpretação dos textos analisados pelo pesquisador ao fornecer um padrão simplificado dos conteúdos dos textos em função do levantamento das palavras que mais 
aparecem juntas em uma mesma frase, e calcula a relação entre elas utilizando o método do quiquadrado, dentre outros (SMALLMAN, 2016).

Para automatizar o processamento, o Iramuteq utiliza métodos estatísticos convencionais aplicados às formas reduzidas das palavras encontradas nos textos, como o infinitivo de verbos ou a raiz dos substantivos, analisadas como se fossem uma cadeia ininterrupta de sinais, como letras ou números e independente da pontuação (PLUMECOCQ, 2014).

Dentre as diferentes técnicas disponibilizadas pelo programa para a análise de dados textual, duas utilizam conceitos estatísticos mais robustos: a Classificação Hierárquica Descendente (CHD) e a Análise Fatorial por Correspondência (AFC).

Na CHD, o corpus é divido em diversos Segmentos de Texto (ST), que são agrupados de acordo com a quantidade de palavras e pontuação. Em seguida, são realizados cruzamentos entre os ST e as formas reduzidas das palavras com frequência maior que 4; e de agrupamentos de ST de tamanhos distintos com formas reduzidas selecionadas. O resultado desses cruzamentos são matrizes de frequência, cujo indicador 1 demonstra a presença do termo em determinado ST e 0 a sua ausência. Com isso, a força de aproximação entre as palavras e entre os segmentos de textos são medidos pelo programa com base em múltiplos testes de qui-quadrado de associação e divididas em classes distintas. Após o processamento dos dados e a leitura dos principais registros em cada uma das classes (novamente com o auxílio do qui-quadrado), os clusters são batizados pelo analista em função das características textuais apresentadas (NASCIMENTO; MENANDRO, 2006).

Já a AFC é utilizada para o exame descritivo em matrizes com elevado volume de dados discretos e sem uma estrutura pré-definida, permitindo análises multivariadas e exploratórias em variáveis categóricas (CARVALHO; STRUCHINER, 1992). Nessa técnica, os resultados são disponibilizados graficamente e em tabelas de contingências, possibilitando a observação do grau de interação entre as variáveis em função da distância calculada pelo qui-quadrado dos perfis de linha ou coluna (INFANTOSI; COSTA; ALMEIDA, 2014).

Ressalta-se, contudo, que o uso da ferramenta, por si só, não caracteriza um método e os resultados fornecidos não encerram a análise dos dados (CAMARGO; JUSTO, 2013). Para um melhor entendimento do discurso, com conclusões e inferências mais próximas da realidade, os resultados produzidos pelo programa devem ser interpretados de diferentes maneiras e sempre em conjunto com o texto original (SMALLMAN, 2016). 


\section{Procedimentos metodológicos}

Para a análise textual desta pesquisa, foi avaliada uma amostra dos registros encaminhados por meio do formulário de atendimento da ouvidoria, disponível na página do Inmetro na Internet. O período de coleta foi de $1^{\circ}$ de janeiro a 31 de dezembro de 2016.

No total, foram analisados 12.494 registros, sendo 10.099 pedidos de informações, 2.043 reclamações, 168 denúncias, 143 sugestões, 34 críticas e 7 elogios. A amostra foi composta por pessoas físicas e jurídicas que, de forma espontânea, entraram em contato diretamente com a Ouvidoria do Inmetro para a interposição de demanda.

Ressalta-se que a escolha desse canal específico se deve ao fato de a comunicação ser realizada da forma mais direta possível, sem a interlocução de outros agentes, como atendentes ou direcionadores eletrônicos. $\mathrm{O}$ texto preenchido no formulário encontra-se de maneira original, tal qual o requerente o escreveu, expressando exatamente o seu ponto de vista sobre o assunto. Além disso, qualquer pessoa pode encaminhar suas demandas por meio deste formulário, sem a necessidade de um cadastro prévio.

Para a análise dos textos, foi utilizado o programa Iramuteq, específico para o exame computacional de conteúdo lexical. As técnicas realizadas neste estudo foram a Classificação Hierárquica Descendente (CHD) e Análise Fatorial por Correspondência (AFC).

Conforme recomendação de Camargo e Justo (2016), por não contribuírem para o objeto de estudo, diversos elementos foram removidos para a composição e limpeza da base de dados textual de análise (corpus), por exemplo, saudações, agradecimentos, e-mails, nomes próprios etc. Também foi feita a correção ortográfica dos termos utilizados. As classes gramaticais levadas em consideração foram: adjetivos, formas não reconhecidas, substantivos e verbos (formas ativas); substantivos e verbos complementares (formas suplementares). As palavras instrumentos ou de apoio foram desconsideradas.

Vale lembrar que o estudo lexográfico é uma das técnicas utilizadas para a realização da AC (MINAYO, 2014). Todavia, o conhecimento e a relação de proximidade do analista com o texto objeto de estudo é relevante para definir o contexto e a desambiguação dos termos, tarefas que os programas informatizados de tratamento de dados ainda apresentam certas limitações (BARDIN, 2011).

Seguindo essas orientações, parte do material estudado precisou ser avaliada separadamente, de forma a mitigar possíveis variações na interpretação dos resultados apresentados pelo programa. 
Por fim, ressalta-se que as informações das bases de dados foram analisadas de forma conjunta, sem a possibilidade de identificação individual, preservando e assegurando o sigilo das informações conforme exigência legal prevista no artigo 31, parágrafo $3^{\circ}$, inciso II da Lei $\mathrm{n}^{\mathrm{o}} 12.527$, de 18 de novembro de 2011 - Lei de Acesso à Informação.

Além disso, não foi objeto de estudo o mérito das solicitações, mas somente os elementos textuais e os termos utilizados para o registro da demanda no canal de atendimento.

\section{AnÁlise QUANTitativa}

Na verificação inicial dos registros pelo programa Iramuteq, verificou-se que o texto base (corpus textual) é composto de um total de 1.127.036 palavras, separadas pelo próprio programa em 32.065 segmentos de textos (ST). No total, foram identificadas 42.409 formas lematizadas (raiz de palavras que se repetem ao longo do texto) e 18.968 formas de ocorrência única (hapax).

Para a primeira análise do corpus textual deste estudo, foi utilizada a técnica de Classificação Hierárquica Descendente, que avalia o grau de semelhança e de distanciamento entre os vocábulos nos segmentos de textos sem levar em consideração as categorias em que estavam originalmente registradas. Para essa avaliação, o sistema foi capaz de equiparar e reclassificar 28.902 segmentos de textos $(90,14 \%$ do total) em 5 clusters, conforme demonstrado na Figura 1, o Dendograma.

Figura 1 - Dendograma da CHD dos registros da Ouvidoria

\begin{tabular}{|c|c|c|c|c|}
\hline classe 4 & classe 3 & classe 2 & classe 1 & classe 5 \\
\hline $\begin{array}{c}\text { ORQUESTRA } \\
20.5 \% \\
\end{array}$ & $\begin{array}{c}\text { PÓS-VENDA } \\
21.6 \% \\
\end{array}$ & $\begin{array}{l}\text { LABORATORIOS } \\
\text { ACREDITADOS } \\
14.9 \%\end{array}$ & $\begin{array}{l}\text { PRODUTOS E } \\
\text { SERVIÇOS } \\
22.3 \%\end{array}$ & $\begin{array}{l}\text { EXPURGO } \\
20.7 \% \\
\end{array}$ \\
\hline $\begin{array}{l}\text { orquestra } \\
\text { processo } \\
\text { dia } \\
\text { registro } \\
\text { sistema } \\
\text { pagamento } \\
\text { gru } \\
\text { deferimento } \\
\text { licença } \\
\text { momento } \\
\text { ler } \\
\text { solicitar } \\
\text { tarefa } \\
\text { deferir } \\
\text { renovaça } \\
\text { prazo } \\
\text { objeto }\end{array}$ & $\begin{array}{l}\text { comprar } \\
\text { marca } \\
\text { colocar } \\
\text { criancas } \\
\text { defeito } \\
\text { loja } \\
\text { vender } \\
\text { carro } \\
\text { trocar } \\
\text { acidente } \\
\text { casa } \\
\text { usar } \\
\text { filho } \\
\text { risoo } \\
\text { só } \\
\text { troca } \\
\text { compra } \\
\text { bebé } \\
\text { carrinho }\end{array}$ & $\begin{array}{l}\text { laboratório } \\
\text { calibraçăo } \\
\text { iso } \\
\text { ensaio } \\
\text { acreditação } \\
\text { nbr } \\
\text { norma } \\
\text { instrumento } \\
\text { rbc } \\
\text { verificaçằo } \\
\text { acreditado } \\
\text { acreditar } \\
\text { mediçăo } \\
\text { calibrar } \\
\text { medidor } \\
\text { aferiçăo } \\
\text { abnt } \\
\text { curso }\end{array}$ & $\begin{array}{l}\text { produto } \\
\text { certificação } \\
\text { portaria } \\
\text { se } \\
\text { inmetro } \\
\text { saber } \\
\text { compulsório } \\
\text { dever } \\
\text { fabricante } \\
\text { dúvida } \\
\text { conformidade } \\
\text { informaçăo } \\
\text { selo } \\
\text { item } \\
\text { comercializar } \\
\text { importar } \\
\text { regulamento } \\
\text { resolunäo }\end{array}$ & $\begin{array}{l}\text { ouvidoria } \\
\text { cep } \\
\text { tel } \\
\text { enviar } \\
\text { endereço } \\
\text { rua } \\
\text { email } \\
\text { br } \\
\text { fax } \\
\text { ativo } \\
\text { metrologia } \\
\text { bairro } \\
\text { Itda } \\
\text { tecnologia } \\
\text { instituto } \\
\text { reavaliação }\end{array}$ \\
\hline
\end{tabular}

Fonte: dos autores. 
Por meio da CHD, foi possível definir uma nova tipologia de classificação dos registros. Para tanto, os segmentos de texto foram reagrupados de acordo com a frequência e força de aproximação entre as palavras e entre os segmentos de texto, novamente com base no coeficiente de qui-quadrado $\left(\mathrm{x}^{2}\right)$. Após o processamento dos dados e leitura dos principais registros em cada uma das classes, os clusters foram rebatizados em função das características textuais apresentadas.

A Classe 1 foi denominada "Produtos e Serviços", e foi a que mais agrupou ST, com 22,3\% de incidência. Trata-se basicamente dos pedidos de informações sobre produtos e serviços certificados pelo Inmetro, como equipamentos elétricos, máquinas agrícolas, termômetros, embalagens, lâmpadas leds. Nesta classe também há diversas dúvidas com relação às Portarias do Inmetro e sua aplicação, principalmente de pessoas jurídicas interessadas em importar e comercializar produtos de certificação compulsória. Além disso, busca-se nessa categoria sanar dúvidas com relação às marcas do Inmetro nos produtos, como selos e etiquetas, tanto com relação ao processo de aquisição, como também a confirmação da obrigatoriedade e veracidade do mesmo. Abaixo, são descritos alguns exemplos que caracterizam essa nova categoria:

Desejo saber se os pinos de locks que sustentam os containers necessitam da certificação junto ao Inmetro, e como devo proceder caso haja regulamentação (REQUERENTE 1).

Tenho uma dúvida sobre a portaria de que trata da verificação do conteúdo líquido de produtos pré-medidos (REQUERENTE 2).

No caso de uma eventual fiscalização do Inmetro, questiono se é passível de autuação. Solicito orientações, pois li as portarias que tratam da certificação dos produtos em questão e não localizei tal informação (REQUERENTE 3).

A Classe 2, denominada de "Laboratórios Acreditados", possui 14,9\% de incidência nos textos analisados e está fortemente relacionada à Classe 1. Trata de três tipos de solicitações. A primeira refere-se a dúvidas dos proprietários dos laboratórios com relação ao processo de certificação e aquisição de etiquetas. A segunda, de solicitações de contatos de laboratórios acreditados pelo Inmetro para a realização de calibração ou ensaio em produtos e serviços com certificação compulsória. Por fim, a Classe 2 também aporta denúncias sobre laboratórios que não estão em dia com as exigências do Inmetro para a certificação. Como exemplo, podemos citar:

Estou tentando me credenciar junto ao Inmetro para acreditação de organismos de certificação de produtos ABNT-NBR-ISO-IEC de nosso laboratório de calibração (REQUERENTE 4). 
Gostaria de saber onde posso encontrar a relação de laboratórios acreditados pelo Inmetro, de acordo com a norma ABNT-NBR-ISO-IEC, que realizem exames toxicológicos que atendam a portaria $n^{o}[\ldots]$ (REQUERENTE 5).

A Classe 3 refere-se ao "Pós-venda" e contempla 21,6\% dos ST. São consumidores que já adquiriram algum produto e estão com dúvida sobre a certificação do Inmetro ou reclamações com relação à qualidade dos mesmos. Também englobam algumas sugestões para o Inmetro testar determinados produtos e serviços. São exemplos dessas requisições:

Comprei um pacote de papel dessa marca e me senti lesada, primeiro quando abri vi um papel muito feio pequeno de altura sem acabamento achei estranho quando coloquei no suporte pois ele ficou muito pequenino (REQUERENTE 6).

Comprei um secador da marca [...] que em um ano já foi trocado três vezes, pois sempre apresenta defeito (REQUERENTE 7).

Comprei um jogo de pneus aro 15 da marca [...] em de abril de 2016 na loja [...] e para minha surpresa, com meses de uso o pneu dianteiro do lado direito do passageiro esvaziava e nós enchíamos e nessa semana o pneu estourou sem nenhum motivo aparamente quase causando um acidente (REQUERENTE 8).

Gostaria de sugerir a fiscalização das garrafas térmicas vendidas no mercado. Já comprei de diferentes marcas e nenhuma segura o calor durante o tempo necessário algumas não seguram o calor nem por horas (REQUERENTE 9).

A Classe 4, denominada simplesmente de "Orquestra", refere-se quase que exclusivamente a reclamações ou pedidos de informação de empresas sobre o Sistema Orquestra, de responsabilidade do Inmetro, para acompanhar os registros de certificação em produtos ou serviços. Os exemplos que melhor caracterizam essa categoria são:

Informo que estou em processo de licença de importação junto à anuência, já efetuei o pagamento da GRU, como valor de [...], porém até a presente data este pagamento não consta no sistema Orquestra (REQUERENTE 10).

Dei entrada ao processo de deferimento de licença de importação no dia [...] e apareceu como deferida no sistema Orquestra, porém até a presente data não consta no Siscomex (REQUERENTE 11).

Estamos com o processo parados devido ao problema no sistema Orquestra de não reconhecer o pagamento das taxas para posterior análise e deferimento das licenças de importação. O boleto foi pago no dia e até hoje consta no sistema aguardando pagamento (REQUERENTE 12).

O quinto e último cluster, denominado "Expurgo", acolhe segmentos de textos variados que não se encaixam em nenhuma categoria específica, formando uma base contendo principalmente os dados de contatos dos solicitantes. 
A segunda parte do estudo dos registros pelo programa Iramuteq foi realizada por meio da Análise Fatorial por Correspondência.

Essa técnica permite a representação das relações entre as classes em um plano cartesiano de acordo com a frequência de incidência das palavras em seus respectivos clusters (1 a 5) e a interação entre eles por meio da sua localização no gráfico (NASCIMENTO; MENANDRO, 2006).

Assim, no presente estudo, o plano foi dividido em cinco fatores, conforme observado na Figura 2.

Figura 2 - AFC por Classe dos registros da Ouvidoria

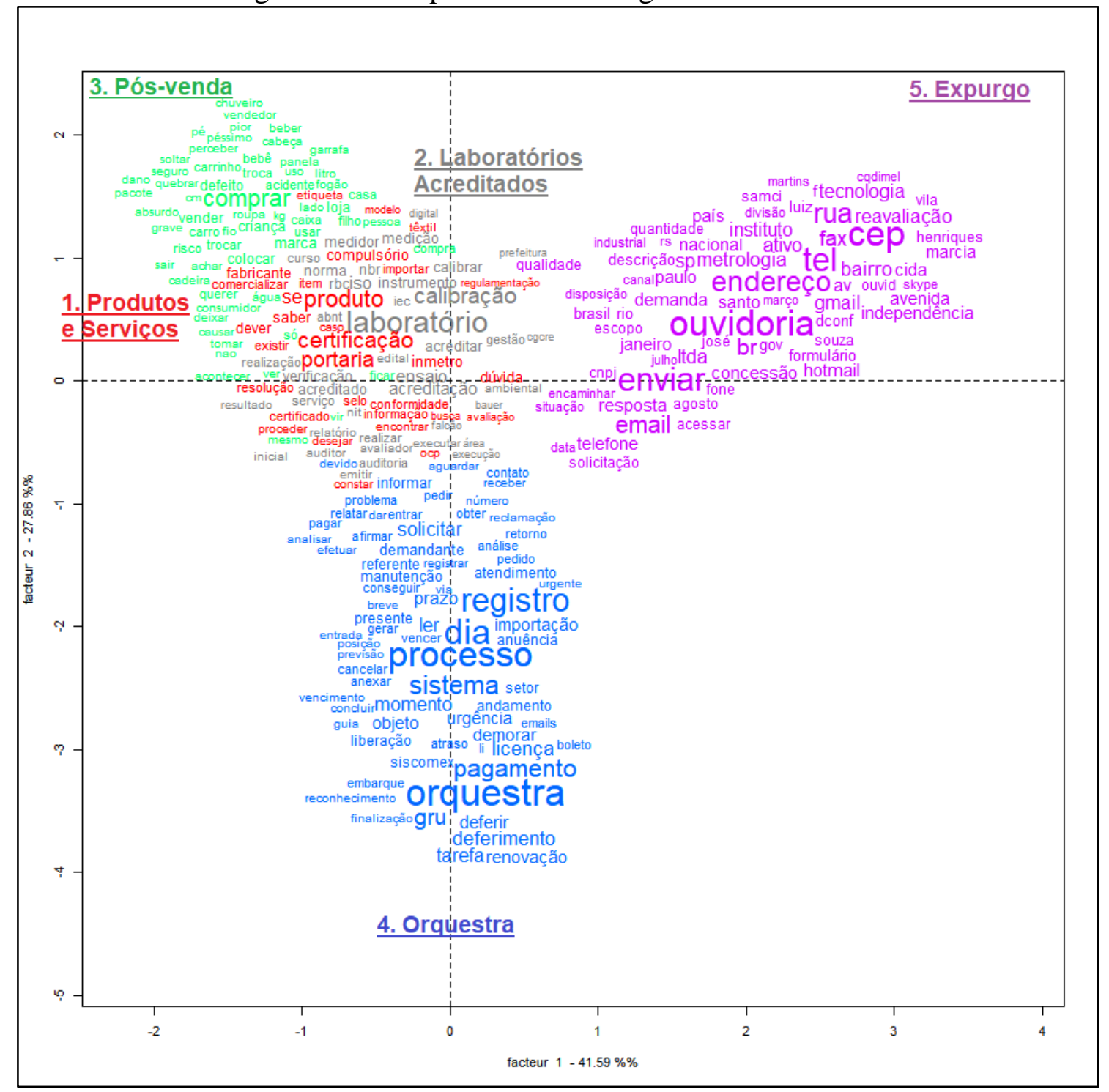

Fonte: dos autores.

A partir dessas informações, observa-se uma significativa proximidade entre as Classes 1, 2 e 3. Nelas, os termos utilizados nos requerimentos encontram-se dispostos de forma intercalada e misturada em relação ao plano, concentrando-se do centro ao canto superior esquerdo do gráfico. 
Desta forma, com base no coeficiente de qui-quadrado $\left(\mathrm{x}^{2}\right)$, verifica-se que as categorias Produtos e Serviços, Laboratórios Acreditados e Pós-venda possuem características lexicais próprias, que as particularizam em relação ao todo.

Nesta macroárea, as Classes que mais se assemelham são a 1 (Produtos e Serviços) e a 2 (Laboratórios Acreditados). Por tratarem basicamente de serviços prestados pelos Inmetro, essas categorias compartilham o material semântico em suas solicitações, com grande parte advinda de proprietários ou representantes de empresas.

Já a Classe 3 (Pós-venda), refere-se ao consumidor final, que já adquiriu algum produto e não demonstra satisfação com o mesmo, sendo que a maior parte dos termos utilizados estão concentrados no canto superior esquerdo do gráfico. A palavra lematizada "comprar" aparece com a maior frequência relativa na Classe.

Em oposição a essas, no plano inferior do gráfico, destaca-se a Classe 4, específica do Sistema Orquestra.

Também aqui o Iramuteq agrupou em uma Classe específica (Expurgo), diversos termos com pouca relevância analítica para este estudo. Esta se encontra em oposição a todas as demais Classes analisadas no plano, ocupando o canto superior direito do gráfico.

Por fim, ressalta-se que o Fator (facteur) 1 acomodou os elementos de forma mais intensa $(41,59 \%)$, o que torna mais significativa a análise do eixo horizontal das disposições das palavras no plano. Somando-se esse resultado ao Fator 2 (27,86\%), temos aproximadamente $70 \%$ de acomodação dos termos analisados sobre esses eixos do gráfico da Figura 2.

\section{Análise QUalitativa e PROPOSTA de APliCaÇão}

Com o auxílio do programa de análise lexical Iramuteq foi possível reconhecer diferentes padrões de solicitações, que vão além da forma de classificação comumente utilizada pelos canais de atendimento (informação, solicitação, denúncia, reclamação, elogio e sugestão).

O estudo dos padrões e do perfil das solicitações permitiu a reclassificação da base de solicitações em 4 clusters principais: "Produtos e Serviços", "Laboratórios Acreditados", "Pósvenda" e "Orquestra". Cada uma dessas novas categorias possui características próprias, relacionadas diretamente as necessidades de seus demandantes.

Assim, com base na análise qualitativa dessas informações foi possível levantar algumas oportunidades de melhorias para o aprimoramento do atendimento prestado pela ouvidoria aos usuários de seus serviços. 
Primeiramente, a tipologia proposta pode ser empregada na organização das unidades de atendimentos. Assim, os atendentes seriam capacitados por assuntos específicos de competência do órgão, e não pela classificação genérica por tipo de demanda. Por conseguinte, haveria um direcionamento mais preciso dos requerentes.

A análise qualitativa das informações permitiu o detalhamento do atendimento de cada cluster, conforme segue:

- Em "Produtos e Serviços", voltado principalmente para as empresas, incluiria informações sobre as portarias e normas, de forma detalhada, e na resolução de dúvidas sobre os produtos certificados e também sobre os serviços ofertados pelo órgão.

- Para "Laboratório Acreditados", seria disponibilizada a lista atualizada dos laboratórios e serviços, incluindo suas especificações. Também haveria a capacitação sobre como proceder para o recepcionamento de denúncias e dúvidas relacionadas à acreditação.

- Em "Pós-venda", direcionado principalmente ao consumidor pessoa física, seriam revisadas as informações sobre os produtos regulamentados, além da adequação para tratar sobre acidentes de consumo ou sugestão de produtos que poderiam ser testados pela Instituição.

- Também seriam capacitadas pessoas para atender os usuários do sistema "Orquestra", com foco nos problemas e dúvidas mais recorrentes, além de um espaço para que o atendente pudesse acessar de forma on-line as informações do usuário no sistema.

A nova tipologia também pode ser utilizada para orientar futuras ações de treinamento e capacitação, focadas nas características de cada Classe, de forma a agilizar o processo de atendimento. Assim, no nosso caso, o conteúdo programático incluiria os principais atributos de cada uma das quatro Classes levantadas pela AC.

\section{CONSIDERAÇÕES FINAIS}

O pleno desenvolvimento democrático sobrevém da conscientização dos cidadãos de suas prerrogativas com relação aos assuntos coletivos, inclusive como parte influenciadora das decisões no âmbito das políticas públicas. Na tentativa de superar a crise de representatividade observada nos tempos atuais, que tem como consequência a alienação política e pública, os canais de participação direta dos entes governamentais fornecem uma alternativa de cooperação que leva em consideração os anseios da sociedade não organizada e estimula o controle social.

Deste modo, a participação social ganha relevância na medida em que a população exija mais e melhores meios de comunicação direta e, principalmente, que sintam que as suas 
necessidades estão sendo de fato consideradas. Além disso, o Estado, ao buscar mecanismos para ampliar a participação direta dos cidadãos em suas ações, cumpre o seu papel institucional de fortalecer e incentivar o exercício da cidadania.

Nesse contexto, a Ouvidoria, vista como um referencial de participação social, possui a missão de aproximar o cidadão dos organismos públicos. Para tanto, deve esforçar-se para atender os anseios da sociedade de forma a criar uma relação de confiança, satisfação e transparência.

Para auxiliar nessa tarefa, o presente estudo se propôs a analisar os registros enviados à página da Ouvidoria do Inmetro na Internet ao longo do ano de 2016, e teve como objetivo categorizar as informações de acordo com a frequência da repetição e posicionamento dos termos linguísticos utilizados nas solicitações à luz da metodologia da Análise de Conteúdo.

Ao se utilizar a metodologia de AC para aperfeiçoar o processo de segmentação, buscou-se enfatizar a gestão por processo na interpretação, classificação e tratamento das informações, segundo a percepção dos próprios usuários do canal.

Por conseguinte, é esperado um aumento na satisfação e na qualidade do retorno dado às manifestações, visto que as demandas serão tratadas de maneira específica, dentro das respectivas Classes. O processo de resolução de problemas e pedidos de informação também é beneficiado. Além disso, a nova tipologia pode orientar ações de treinamento e capacitação focadas nas características das Classes, de forma a auxiliar na assimilação dos principais assuntos recepcionados pela organização e adequar a linguagem utilizada.

Conforme ressaltado por Marcelino e Oliveira (2017), a adaptação da linguagem técnica, comumente utilizada pelas organizações da Administração Pública, em uma forma de comunicação mais próximo ao cidadão é relevante para a redução do hiato entre o legalmente proposto e o que ocorre na realidade.

É importante reforçar que essas análises advêm exclusivamente da base estudada, o que limita o campo de conhecimento e aplicação. Outros fatores externos às demandas também devem ser considerados para a composição final da estrutura de uma ouvidoria.

Além disso, ressalta-se que por ser tratar de um Estudo de Caso, a tipologia apresentada é personalista, não podendo ser diretamente aplicada em outras organizações. Contudo, essa limitação não se aplica à metodologia utilizada no estudo, que poderá ser replicada em outras ouvidorias, sejam do setor público ou privado. 


\section{REFERÊNCIAS}

AZEVEDO, Marcia Carvalho de; CALDAS, Miguel Pinto. O discurso evolucionista e a prática involutiva: um estudo empírico sobre o impacto de mudanças tecnológicas sobre o desenho do trabalho em call centers. Revista de Administração Pública, v. 9, n. 3, set. 2005. p. 33-55.

BARDIN, Laurence. Análise de conteúdo, v.22, 1. ed. São Paulo: Edições 70, 2011.

BARRETO, Francisco Assis Santos Mano. A importância da ouvidoria para o Serviço Público: o caso da previdência social. In: MENEZES, Ronald do Amaral; CARDOSO, Antonio Semeraro Rito (Org.). Ouvidoria pública brasileira: reflexões, avanços e desafios. Brasília: Ipea, 2016. p. 153162.

BOBBIO, Norberto. Estado, governo e sociedade: para uma teoria geral da política. 12. ed. São Paulo: Paz e Terra, 2005.

BRASIL. Controladoria-Geral da União. Manual de ouvidoria pública: rumo ao sistema participativo. Brasília: CGU, 2013.

BRASIL. Ouvidorias: tipos de manifestação. Disponível em:

<www.ouvidorias.gov.br/cidadao/faca-sua-manifestacao/tipos-de-manifestacao>. Acesso em: 11 jan. 2018.

CAMARGO, Brígido Vizeu.; JUSTO, Ana Maria. Iramuteq: um software gratuito para análise de dados textuais. Temas em Psicologia, v. 21, n. 2, 2013. p. 513-518.

CAMARGO, Brígido Vizeu; JUSTO, Ana Maria. Tutorial para uso do software Iramuteq. Laboratório de Psicologia Social da Comunicação e Cognição. Universidade Federal de Santa Catarina, 2016.

CARVALHO, Marília Sá; STRUCHINER, Cláudio José. Análise de correspondência: uma aplicação do método à avaliação de serviços de vacinação. Cadernos de Saúde Pública, v. 8, n. 3, 1992. p. 287-301.

CHARTIER, Jean-François; MEUNIER, Jean-Guy. Text mining methods for social representation analysis in large corpora. Papers on Social Representations, v. 20, n. 37, 2011. p. 1-37.

CRESWELL, John W. Projeto de pesquisa: métodos qualitativo, quantitativo e misto. 2. ed. Porto Alegre: Artmed, 2007.

FREGONEZE, Gisleine Bartolomei et al. Metodologia científica. Londrina: Editora e Distribuidora Educacional S.A, 2014.

INFANTOSI, Antonio Fernando Catelli; COSTA, João Carlos da Gama Dias; ALMEIDA, Renan Moritz Varnier Rodrigues. Análise de correspondência: bases teóricas na interpretação de dados categóricos em Ciências da Saúde. Questões Metodológicas, v. 30, n. 3, 2014. p. 473-486.

MARCELINO, Carolina Wunsch; OLIVEIRA, Samir Adamoglu. Lei e linguagem: mecanismos dificultadores à adoção e cumprimento da lai em nível municipal. Cadernos de Linguagem e Sociedade, v. 18, n. 3, 2017. p. 174-195. 
MENEZES, Ronald do Amaral. Projeto coleta OGU 2014. Brasília: Ipea, 2016.

MILANI, Carlos Roberto Sanchez. O princípio da participação social na gestão de políticas públicas locais: uma análise de experiências latino-americanas e européias. Revista de Administração Pública, v. 42, n. 3, 2008. p. 551-579.

MINAYO, María Cecília de Souza. O desafio do conhecimento: pesquisa qualitativa em saúde. 14. ed. São Paulo: Hucitec, 2014.

MORGAN, Gareth. Imagens da organização. 2. ed. São Paulo: Atlas, 2006.

NASCIMENTO, Adriano Roberto Afonso; MENANDRO, Paulo Rogério Meira. Análise lexical e análise de conteúdo: uma proposta de utilização conjugada. Estudos e Pesquisas em Psicologia, v. 6, n. 2, 2006. p. 72-88.

PEIXOTO, Stefano Frugoli; MARSIGLIA, Regina Maria Giffoni; MORRONE, Luiz Carlos. Atribuições de uma ouvidoria: opinião de usuários e funcionários. Saúde e Sociedade, v. 22, n. 3, 2013. p. 785-794.

PLUMECOCQ, Gaël. The second generation of ecological economics: how far has the apple fallen from the tree? Ecological Economics, v. 107, 2014. p. 457-468.

POGREBINSCHI, Thamy; SANTOS, Fabiano. Participação como representação: o impacto das Conferências Nacionais de Políticas Públicas no Congresso Nacional. DADOS - Revista de Ciências Sociais, v. 54, n. 3, 2011. p. 259-305.

RABELO, Marcia Christina dos Santos; ALENCAR, Joana Luiza Oliveira. Ouvidorias públicas no contexto do Novo Serviço Público: o caso da ouvidoria da Receita Federal do Brasil - $1^{\text {a }}$ Região fiscal. In: MENEZES, Ronald do Amaral; CARDOSO, Antonio Semeraro Rito (Org.). Ouvidoria Pública Brasileira: reflexões, avanços e desafios. Brasília: Ipea, 2016. p. 203-214.

RAUPP, Fabiano Maury. Realidade da transparência passiva em prefeituras dos maiores municípios brasileiros. Revista Contemporânea de Contabilidade, v. 13, n. 30, 2016. p. 34-52.

SILVA, Adriana Campos et al. Por um Sistema Nacional de Ouvidorias Públicas: possibilidades e obstáculos. Série Pensando o Direito, v. 42. Brasília: Ministério da Justiça, 2012.

SMALLMAN, Melanie. Public understanding of science in turbulent times III: deficit to dialogue, champions to critics. Public Understanding of Science, v. 25, n. 2, fev. 2016.

SOARES, Evanna. Audiência pública no processo administrativo. Revista de Direito Administrativo, v. 229, 2002. p. 259-283. 